\title{
Effects of Alloying Elements on Martensitic Transformation Behavior and Damping Capacity in Fe-17Mn Alloy
}

\author{
S.H. Baik, J.C. Kim, K.K. Jee*, W.Y. Jang** and M.C. Shin* \\ Woojin Inc., Research Institute of Measuring Technology, C.P.O. Box 6666, Seoul, Korea \\ * Korea Institute of Science of Technology, Division of Metals, Seoul 136-791, Korea \\ ** Chosun University, Department of Metallurgical Engineering, Kwangju 501-759, Korea
}

\begin{abstract}
Effect of carbon and $\mathrm{Ti}$ on $\gamma \leftrightarrow \varepsilon$ martensitic transformation behavior and damping capacity has been investigated in an Fe-17Mn alloy.

The suppressive force of carbon against $\gamma \rightarrow \varepsilon$ transformation increases linearly with an increase in carbon content, lowering $\mathrm{M}_{\mathrm{s}}$ temperature and volume fraction of $\varepsilon$ martensite. Carbon deteriorates damping capacity by reducing the area of $\gamma / \varepsilon$ interfaces and by decreasing the mobility of the interfaces operated as damping source. The reduction in the mobility of the interfaces is accelerated when carbon-containing alloy is aged at high temperatures.

The effect of $\mathrm{Ti}$ on the damping capacity is found to be beneficial in carbon-containing alloy, because the $\mathrm{Ti}$ contributes to depletion of carbon solute by the formation of $\mathrm{TiC}$.
\end{abstract}

\section{INTRODUCTION}

Thermoelastic martensitic alloys which experience phase boundary movement by deformation have been found to exhibit shape memory effect as well as internal friction[1,2]. Discovery of shape memory effect in Fe-Mn based alloys[3,4] undergoing non-thermoelastic $\gamma \leftrightarrow \varepsilon$ martensitic transformation raise a possibility that the alloys can absorb mechanical energy by internal friction.

Recently, some authors have reported damping property in Fe-Mn-Si-Cr[5], Fe-Ni-Mn[6] and Fe-Mn-Si[7] alloys deformed to stress-induced $\varepsilon$ martensite. Though the proposed mechanism of damping capacity is a little different by authors, stress-induced $\varepsilon$ martensite is responsible in common. In previous work, we have reported that $\mathrm{Fe}-\mathrm{Mn}$ alloys show a good damping capacity which is caused by $\varepsilon$ martensite formed on cooling $[8,9]$. The alloys have advantages of good mechanical properties and a low cost over non-ferrous damping alloys such as $\mathrm{Mn}-\mathrm{Cu}[10]$ and $\mathrm{Ni}-\mathrm{Ti}[11]$. In commercial fabrication process, however, introduction of carbon is unavoidable because a large part of scrap which bears carbon is used. But the effect of carbon on the characteristics has not been clarified yet in the alloys.

In this study, the influence of carbon on the $\gamma \rightarrow \varepsilon$ martensitic transformation and damping capacity is investigated by adding carbon to an $\mathrm{Fe}-17 \mathrm{Mn}$ alloy reported to exhibit the highest damping capacity in the Fe-Mn alloy system[8,9]. Moreover, the addition of $\mathrm{Ti}^{\mathrm{i}}$ is made in an attempt to reduce the detrimental effect of carbon, to damping capacity.

\section{EXPERIMENTAL}

The analyzed compositions of the alloys used in this study are listed in Table 1 , carbon is varied 0.02 to $0.28 \mathrm{wt} \%$ in the $\mathrm{Fe}-17 \mathrm{Mn}$ alloy and up to $1.3 \mathrm{wt} \% \mathrm{Ti}$ is added to the $\mathrm{Fe}-17 \mathrm{Mn}-0.2 \mathrm{C}$ alloy.

Table 1. Chemical composition of the alloys used.(wt.\%)

\begin{tabular}{|c|c|c|c|c|c|c|c|}
\hline Alloy No. & 1 & 2 & 3 & 4 & 5 & 6 & 7 \\
\hline $\mathrm{Mn}$ & 17.68 & 17.84 & 17.86 & 17.32 & 17.88 & 17.81 & 17.56 \\
\hline $\mathrm{C}$ & 0.02 & 0.10 & 0.20 & 0.28 & 0.20 & 0.21 & 0.21 \\
\hline $\mathrm{Ti}$ & - & - & - & - & 0.43 & 0.82 & 1.31 \\
\hline $\mathrm{Fe}$ & bal. & bal. & bal. & bal. & bal. & bal. & bal. \\
\hline
\end{tabular}

The alloys were prepared by melting in an induction furnace with the addition of recarburizer. The resulting ingots were homogenized at $1150^{\circ} \mathrm{C}$ for $24 \mathrm{hrs}$ before being hot rolled to bars and plates which 
were then machined into specimens. After solution treatment at $1050^{\circ} \mathrm{C}$ for $1 \mathrm{hr}$, the specimens were quenched into water.

The damping specimen had a total length of $186 \mathrm{~mm}$ with a reduced portion $7 \mathrm{~mm}$ in diameter and

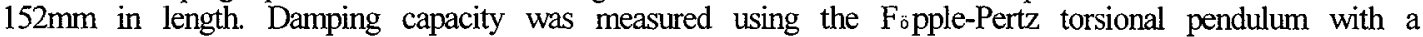
resonance frequency of $12 \mathrm{~Hz}$, and evaluated as the specific damping capacity (SDC)[12]. Transformation temperatures such as $M_{s}, A_{s}$ and $A_{f}$ were determined using a thermo-mechanical analyzer, based on the volume contraction accompanying $\gamma \rightarrow \varepsilon$ transformation. The volume fraction of $\varepsilon$ martensite was measured by comparing the intergrated intensities of $(002) \gamma$ and $(1011) \varepsilon$ peaks in X-ray diffraction. The TEM specimens were prepared by electropolishing with twin-jet in a $10 \% \mathrm{HClO}_{4} /$ methanol solution. The electron microscope used was Philips CM-30 with an accelerating voltage of $300 \mathrm{kV}$.

\section{RESULTS}

Fig.1 represents the variation in transformation temperatures with carbon content. As carbon content increases, $M_{s}$. temperature decreases, indicating that carbon suppresses significantly $\gamma \rightarrow \varepsilon$ transformation. The suppressive effect of carbon against $\gamma \rightarrow \varepsilon$ transformation is also confirmed by Fig.2 which shows the change in amount of $\varepsilon$ martensite with carbon content measured by X-ray diffraction.

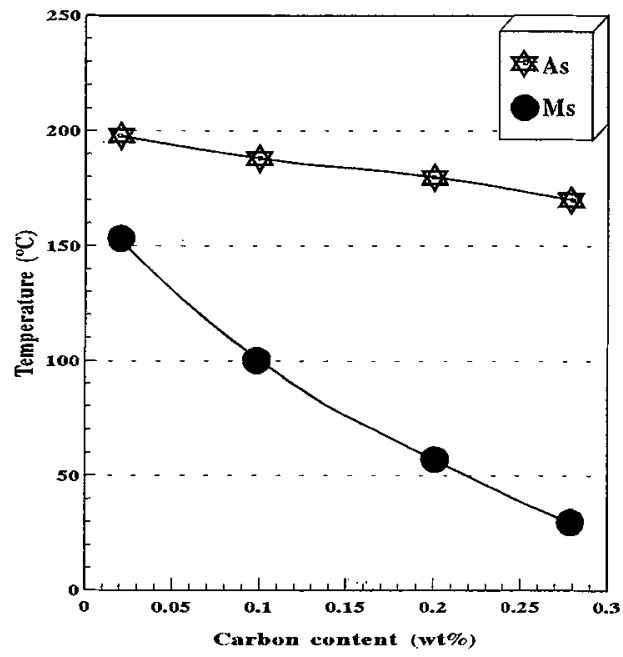

Fig.1 Variation of transformation temperatures with carbon content in water-quenched $\mathrm{Fe}-17 \% \mathrm{Mn}-\mathrm{X} \% \mathrm{C}$ alloy.

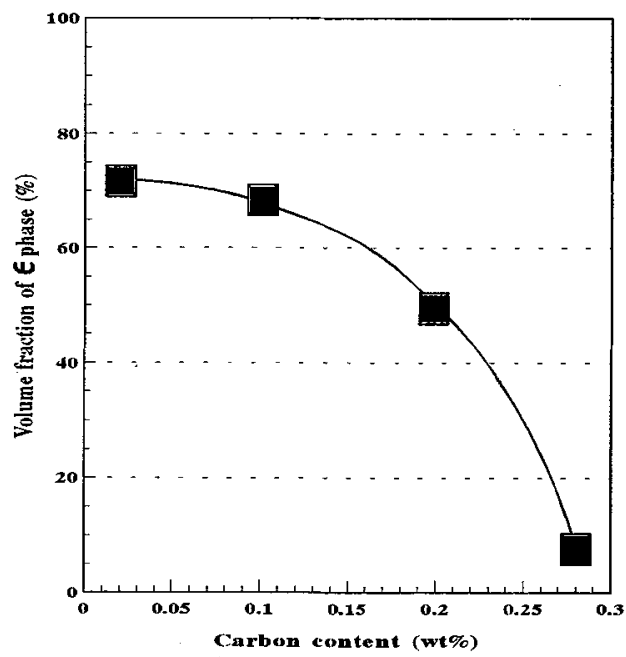

Fig.2 Variation of amount of epsilon phase with carbon content in water-quenched $\mathrm{Fe}-17 \% \mathrm{Mn}-\mathrm{X} \% \mathrm{C}$ alloy.

Transmission electron micrographs of three alloys with a different carbon content in Fig. 3 reveals that the number of $\varepsilon$ plates decreases with increasing carbon content. The $\mathrm{Fe}-1 \mathrm{MMn}-0.02 \mathrm{C}$ and Fe-17Mn-0.1C alloys consist of stacking faults and $\varepsilon$ plates with several variants in $\gamma$ matrix. With futher increase in carbon content, as shown in Fig.3(c), tiny stacking faults and $\varepsilon$ plates with only a little amount are observed. However, as previously reported in a Fe-17Mn-6Si-0.3C alloy[13], no formation of carbides occurs.

The effect of $\mathrm{Ti}$ addition to the $\mathrm{Fe}-17 \mathrm{Mn}-0.2 \mathrm{C}$ alloy on the transformation temperatures is shown in Fig.4. $\mathrm{M}_{\mathrm{s}}$ temperature increases with increasing $\mathrm{Ti}$ content, indicating that $\mathrm{Ti}$ alleviates the suppressive force of carbon against $\gamma \rightarrow \varepsilon$ transformation. The addition of Ti to a carbon-free Fe-17Mn alloy, in our preliminary work, hardly creates any change in transformation behavior such as $M_{s}$ temperature or volume fraction of $\varepsilon$ martensite. The role of $\mathrm{Ti}$ appears significantly when it is added to carbon-bearing alloys.

Fig.5 represents the variation of damping capacity with carbon content in the $\mathrm{Fe}-17 \mathrm{Mn}-\mathrm{X} \% \mathrm{C}$ alloys. Damping capacity of the alloys is kept almost constant up to $0.1 \% \mathrm{C}$, however, followed by a steep decrease on further increase in carbon content. The addition of Ti, as shown in Fig.6, is found to improve damping capacity in the $\mathrm{Fe}-17 \mathrm{Mn}-0.2 \mathrm{C}$ alloy, suggesting that $\mathrm{Ti}$ lessens the the detrimental effect of carbon to damping capacity.

Carbon atoms worsen damping property with time as well. Shown in Fig.7 is the change in damping capacity measured at room temperature after the alloys being subjected at $80^{\circ} \mathrm{C}$ for various time. The $\mathrm{Fe}-17 \mathrm{Mn}-0.2 \mathrm{C}$ alloy suffers significantly the drop in damping capacity while the $\mathrm{Fe}-17 \mathrm{Mn}-0.02 \mathrm{C}$ alloy is 
immune to the aging effect. The addition of $\mathrm{Ti}$ keeps also damping capacity in the carbon-containing alloy from the aging effect, in the Fe-17Mn-0.2C-0.8Ti alloy, thus no aging effect take place.

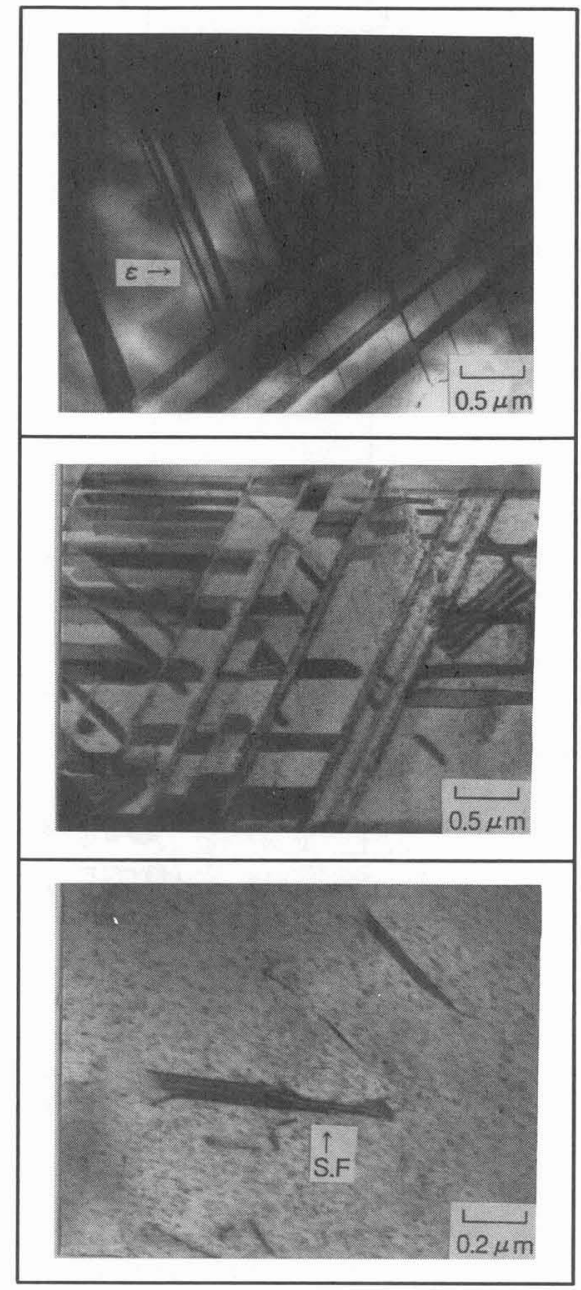

Fig.3 Transmission Electron Micrographs of the water-quenched alloys.

(a) alloy-1 (Fe-17\%Mn-0.02\%C) (b) alloy-2 (Fe-17\%Mn-0.10\%C)

(c) alloy-3 (Fe-17\%Mn-0.28\%

\section{DISCUSSION}

The suppressive force of carbon against $\gamma \rightarrow \varepsilon$ transformation in Fe-Mn alloy can be calculated by thermodynamical consideration as follows. In a Fe-Mn binary alloy system, the free energy difference between $\gamma$ and $\varepsilon$ martensite is expressed as the following equation using a regular solution model[14,15]. $\Delta \mathrm{G}^{\gamma \rightarrow \varepsilon}=\mathrm{X}_{\mathrm{Fe}} \Delta \mathrm{G}_{\mathrm{Fe}}^{\gamma \rightarrow \varepsilon}+\mathrm{X}_{\mathrm{Mn}} \Delta \mathrm{G}_{\mathrm{Mn}}^{\gamma \rightarrow \varepsilon}+\mathrm{X}_{\mathrm{Fe}} \mathrm{X}_{\mathrm{Mn}} \Delta \theta^{\gamma \rightarrow \varepsilon}-\mathrm{-}^{\gamma \rightarrow}$ Shown in Fig. 8 is the temperature dependence of $\Delta \mathrm{G}^{\gamma \rightarrow \varepsilon}$ of the Fe-17Mn alloy obtained using the results of the $\Delta \mathrm{G}_{\mathrm{Fe}}^{\gamma \rightarrow \varepsilon}, \Delta \mathrm{G}_{\mathrm{Mn}}{ }^{\gamma \rightarrow \varepsilon}$ and $\Delta \theta^{\gamma \rightarrow \varepsilon}$ by some authors[16-18]. From the Fig.1, the variation of the $\Delta \mathrm{G}^{\gamma \rightarrow \varepsilon}$ necessary for $\gamma \rightarrow \varepsilon$ transformation with carbon content is obtained as shown in Fig.9. The $\Delta \mathrm{G}$ ${ }_{\gamma \rightarrow \varepsilon}$ is to found to increase linearly with increasing carbon content. The $\Delta \mathrm{G}^{\gamma \rightarrow \varepsilon}$ for a carbon-free Fe-17Mn alloy, estimated to be $90 \mathrm{~J} /$ mole, agrees well with previous result anticipated from the difference between As and Ms[19]. It is noteworthy to compare quantitatively carbon and grain boundary in hindrance to $\gamma \rightarrow \varepsilon$ transformation. It is reported that an Fe-15Mn alloy with a grain size of $1 \mu \mathrm{m}$, besides $90 \mathrm{~J} / \mathrm{mole}$, needs an additional driving force of $150 \mathrm{~J} / \mathrm{mole}[15]$, which is equivalent to $0.09 \% \mathrm{C}$. 


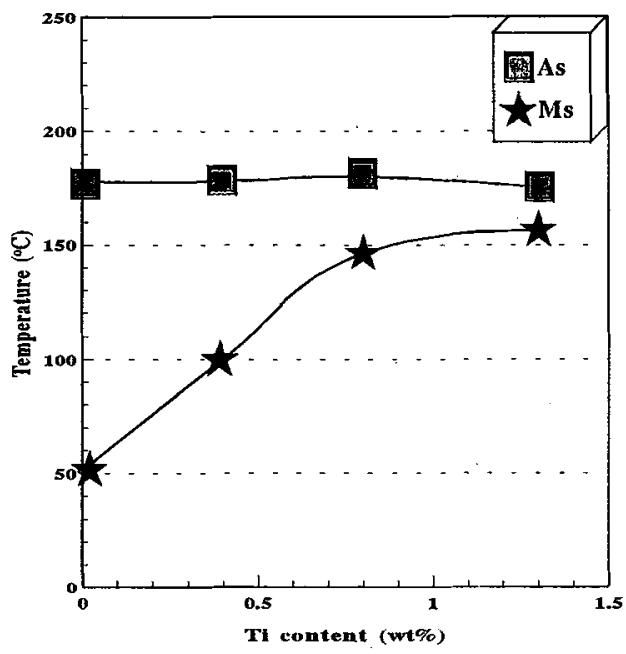

Fig.4 Variation of transformation temperatures with $\mathrm{Ti}$ content in water-quenched $\mathrm{Fe}-17 \% \mathrm{Mn}-\mathrm{X} \% \mathrm{C}$ alloy.

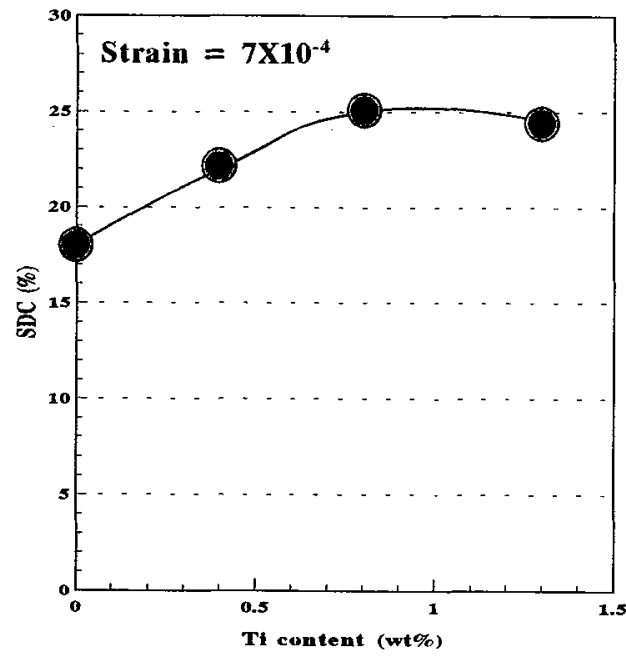

Fig.6 Variation of specific damping capacity with $\mathrm{Ti}$ content in water-quenched $\mathrm{Fe}-17 \% \mathrm{Mn}-0.2 \% \mathrm{C}$ alloy.

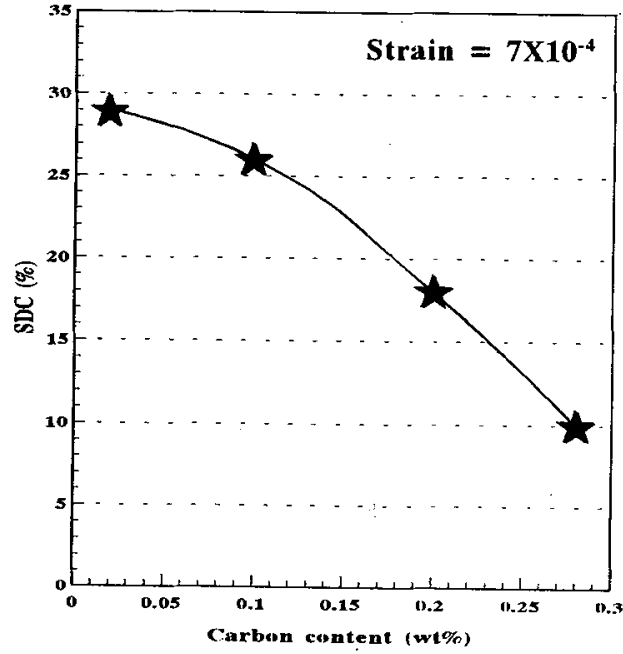

Fig.5 Variation of specific damping capacity with carbon content in water-quenched $\mathrm{Fe}-17 \% \mathrm{Mn}-\mathrm{X} \% \mathrm{C}$ alloy.

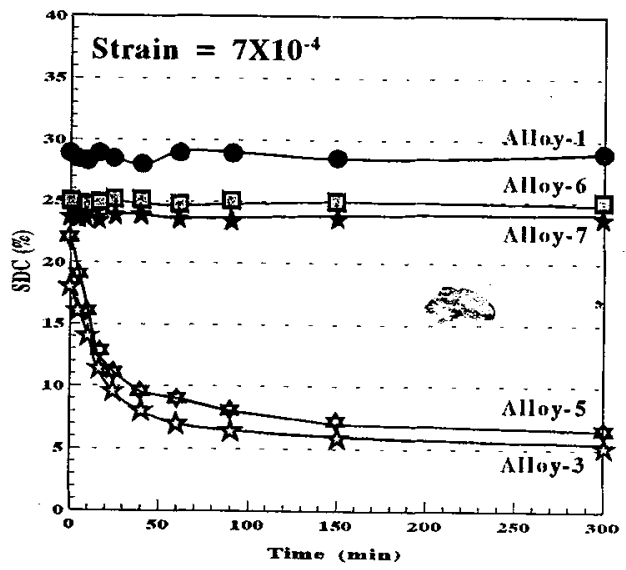

Fig.7 Variation of specific damping capacity with aging time at $80^{\circ} \mathrm{C}$ in $\mathrm{Fe}-17 \% \mathrm{Mn}-\mathrm{X} \% \mathrm{C}-\mathrm{Y} \% \mathrm{Ti}$ alloy.
(a) alloy-1 (Fe-17\%Mn-0.02\%C)
(b) alloy-3 (Fe-17\%Mn-0.2\%
(c) alloy-5 (Fe-17\%Mn-0.2\%C-0.43\%
(d) alloy-6 (Fe-17\%Mn-0.2\%C-0.82\%Ti)
(e) alloy-7 (Fe-17\%Mn-0.2\% $\%$ - $1.31 \% \mathrm{Ti})$

There are two factors contributing to elastic strain on vibration. One is atomic separation and the other is, responsible for damping capacity, irreversible phase boundary movement. Since the shear strain of $\gamma \rightarrow \varepsilon$ transformation in the alloy amounts to tan 19.4 degrees, the boundary movement can generate deformation. The damping mechanism of the alloy may be attributed to the anelastic movement of $\gamma / \varepsilon$ boundaries on vibration. And damping capacity, if assumed to be an increasing function of volume swept by the boundaries, is proportional to the multiplication of the boundary area by travel distance.

The deterioration in damping capacity by the addition of carbon is attributed to the following two reasons. With an increase in carbon content, the volume fraction of $\varepsilon$.martensite decreases as shown in Fig.2, leading to the area reduction of $\gamma / \varepsilon$ boundaries. Secondly, the carbon atoms hinder the movement of $\gamma / \varepsilon$ boundaries by pinning them. 


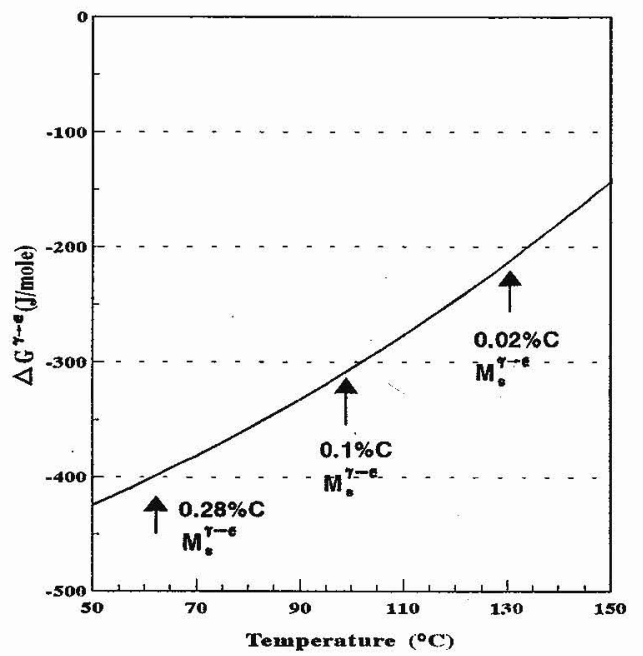

Fig.8 Relation between temperature and the chemical free energy change for austenite to epsilon martensitic transformation.

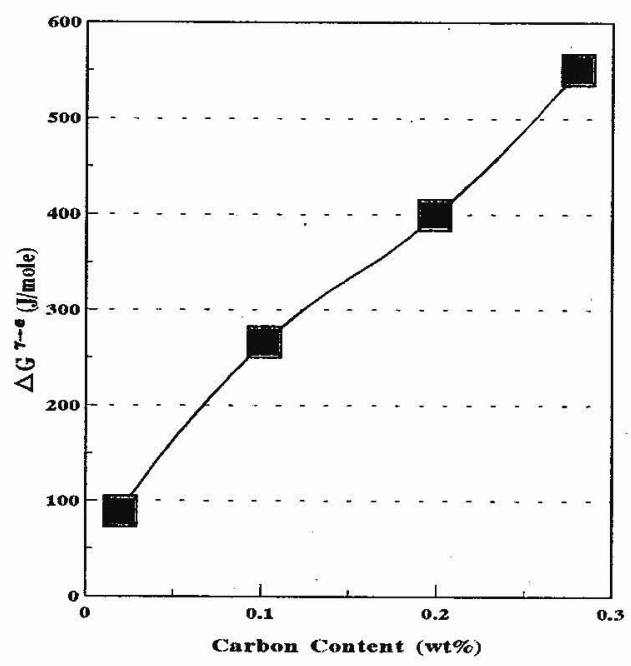

Fig.9 Relation between carbon content and the chemical free energy change as suppressive effect on epsilon martensitic transformation.

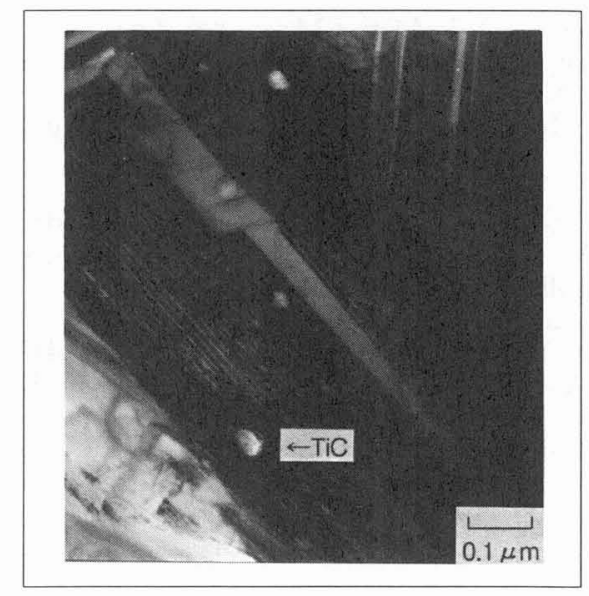

Fig.10 Transmission Electron Micrographs of the water-quenched Fe- $17 \% \mathrm{Mn}-0.2 \% \mathrm{C}-0.8 \% \mathrm{Ti}$ alloy.

The adherence of carbon to the boundaries may be caused by the stress due to the difference in $\mathrm{d}$-spacing between (111) $\gamma$ and (0002) $\varepsilon$ parellel to each other. The d-spacing of $(0002) \varepsilon$, depending on the content of $\mathrm{Mn}$, is about $1.5 \%$ smaller than that of (111) $\gamma$ which is the habit plane. Thus $\gamma$ matrix region near $\gamma / \varepsilon$ boundaries experience tensile stress, acting as the preferential sites for carbon atoms. The carbon atoms collected near the boundaries prevent their movement, aggravating damping capacity. The pinning effect becomes more obvious when the Fe-17Mn-0.2C alloy is aged as in Fig.7, for aging treatment thermally activates carbon atoms to take the preferential sites.

The beneficial effect of $\mathrm{Ti}$ addition to the Fe-17Mn-0.2C alloy in damping capacity is related with the formation of carbides. Fig. 10 shows the transmission electron micrograph of the $\mathrm{Fe}-17 \mathrm{Mn}-0.2 \mathrm{C}-0.80 \mathrm{Ti}$ alloys. Carbides, identified as $\mathrm{TiC}(\mathrm{cubic}, \mathrm{a}=4.33 \AA$ ), are observed in addition to stacking faults and $\varepsilon$ plates. The carbides themselves, without coherency to $\gamma$, seem to block the growth of $\varepsilon$ plates for no 
carbides exist in the $\varepsilon$ plates. The effect of depletion of carbon solute, however, overrides the negative effect of the carbides for the encouragement of $\gamma \rightarrow \varepsilon$ transformation.

\section{CONCLUSION}

1) Carbon is found to suppress significantly $\gamma \rightarrow \varepsilon$ transformation in Fe-Mn alloys, decreasing Ms temperature and volume fraction of $\varepsilon$ martensite.

2) Aggravation in damping capacity by carbon is attributed to the decrease in area of $\gamma / \varepsilon$ boundaries and hindrance to the movement of the boundaries by pinning. Carbon atoms also worsen rapidly damping capacity in the Fe-17Mn-0.2C alloy when the alloy is subjected to aging treatment:

3) The addition of $\mathrm{Ti}$ offsets the suppressive effect of carbon by depleting carbon solute due to the formation of $\mathrm{TiC}$.

\section{Acknowledgments}

The authors wish to acknowledge their grateful thanks to the president S.B.Lee of Woojin OSK Corp. for the financial support of this work.

\section{References}

[1] R. Hashiguti and K. Iwasaki : J. Appl. Phys., 39(1968), 2182.

[2] I. A. Arbuzova, V. S. Gavrilyuk and L. G. Khandros: Fiz. Metal. Metalloved., 27(1969), 1126.

[3] M. Murasaki, H. Otsuka, H. G. Suzuki and S. Matsuda : Proc. of ICOMAT, Nara, (1986), 985.

[4] A. Sato, E. Chishima, K. Soma and T. Mori : Acta Metall., 30 (1982), 1177.

[5] A. Sato, K. Ozaki, Y. Watanabe and T. Mori : Mater. Sci. Eng. A, 101(1988), 25.

[6] S. Watanabe, S. Sato, I. Nakagami and S. Nagashima : Tetsu-to-Hagane, 77 (1991), 523.

[7] K. K. Jee, K. Ito and M. C. Shin : ISIJ int., 34(1994), 912.

[8] C. S. Choi, J. D. Kim, T. H. Cho, S. H. Baik and G. H. Ryu : Proc. of ICOMAT, Monterey, (1992), 509.

[9] C. S. Choi and Woojin OSK Corp. : US Pat., (1994) No. 5290372

[10] L. Wang and T. Ge : Phys. Stat. Sol. (a), 1988, Vol. 105, pp.447-453.

[11] H. C. Lin, S. K. Wu and M. T. Yeh : Met. Trans. A, 1993, Vol. 24A, pp.2189-2194.

[12] A. W. Cochardt : Trans. AIME, 226(1956),1295.

[13] T. Maki : private communication.

[14] M. Murakami and H. Otsuka : Proc. of ICOMAT, Tokyo, (1988), 447.

[15] H. Nakatsu, S. Takaki and Y. Tokunaga : J. Jpn. Inst. Met., 57(1993), 858

[16] L. D. Blackburn, L. Kaufman and M. Cohen : Acta Metall., 13 (1965), 533.

[17] J. F. Breedis and L. Kaufman : Met. Trans., 2 (1971), 2359.

[18] K. Ishida and T. Nishizawa: J. Jpn. Inst. Met., 36 (1972), 1272.

[19] Y. Tomota : Teisu-to-Hagane, 77 (1991), 315. 